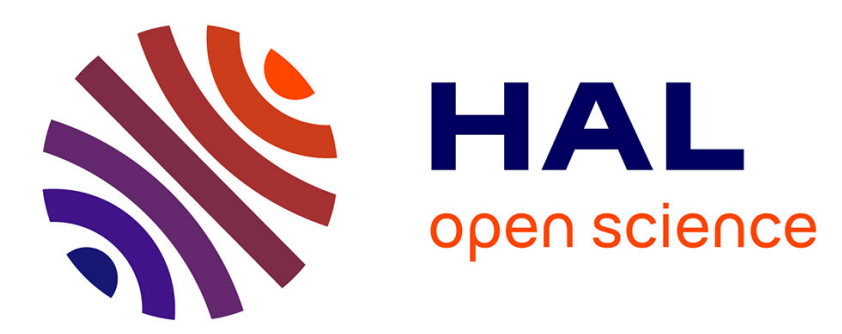

\title{
Magnetic after-effect study of dislocation relaxation in Fe-based alloys
}

B Minov, L Dupré, M J Konstantinović

\section{To cite this version:}

B Minov, L Dupré, M J Konstantinović. Magnetic after-effect study of dislocation relaxation in Fe-based alloys. Journal of Physics D: Applied Physics, 2011, 44 (30), pp.305002. 10.1088/0022$3727 / 44 / 30 / 305002$. hal-00637795

\section{HAL Id: hal-00637795 \\ https://hal.science/hal-00637795}

Submitted on 3 Nov 2011

HAL is a multi-disciplinary open access archive for the deposit and dissemination of scientific research documents, whether they are published or not. The documents may come from teaching and research institutions in France or abroad, or from public or private research centers.
L'archive ouverte pluridisciplinaire HAL, est destinée au dépôt et à la diffusion de documents scientifiques de niveau recherche, publiés ou non, émanant des établissements d'enseignement et de recherche français ou étrangers, des laboratoires publics ou privés. 


\title{
Magnetic after-effect study of dislocation relaxation in Fe-based alloys
}

\author{
B Minov ${ }^{1,2}$, L Dupré ${ }^{2}$ and M J Konstantinović ${ }^{1}$ \\ ${ }^{1}$ Belgian Nuclear Research Centre, SCK•CEN, Boeretang 200, B-2400 Mol, Belgium \\ ${ }^{2}$ Ghent University, Department of Electrical Energy, Systems and Automation, \\ Sint-Pietersnieuwstraat 41, B-9000 Ghent, Belgium \\ E-mail: bminov@sckcen.be
}

\begin{abstract}
Dislocation-related relaxation processes are studied by measuring the magnetic after-effect spectra as a function of temperature in a variety of non-deformed and cold-worked iron alloys. In the $\alpha$ - $\mathrm{Fe}$ and $\mathrm{Fe}-1 \% \mathrm{Cu}$ alloys the peak centered at about $320 \mathrm{~K}$ appears as a consequence of plastic deformation. On the basis of the behavior of its parameters, such as the temperature position of the peak, the full width at half maximum, and the integrated intensities, this feature is assigned to the relaxation process of thermally-activated dislocation motion.
\end{abstract}

PACS numbers: 75.60Lr, 62.40.+i, 61.72Lk, 61.72.J-, 61.72.Yx 


\section{Introduction}

Experimental techniques based on mechanical $[1,2,3]$ and magnetic $[4,5,6,7]$ relaxation phenomena are typically used to study processes related to thermal activation of a variety of lattice defects, in particular those that can be described as point defects. In body-centered-cubic (bcc) $\alpha$-iron, both the Internal Friction (IF) and Magnetic After-Effect (MAE) measurements show the existence of relaxation processes that are assigned to the thermal motion of interstitially-dissolved atoms such as carbon and nitrogen, for example. These so-called Snoek-relaxation peaks appear in the temperature dependent IF and MAE spectra as a consequence of thermally-activated redistribution of interstitials in the lattice [8]. The analysis of the peak parameters, i.e. peak maximum, full width at half maximum (FWHM), and intensity, allows accurate determination of the kinetic parameters, such as the activation energy, distribution of relaxation times and concentration of interstitial atoms, respectively. All parameters extracted from IF and MAE experiments, in the case of both carbon and nitrogen relaxation processes, show excellent agreement with each other [9].

However, clear correspondence between dislocation-relaxation processes in the IF and MAE experiments is not yet established, in spite the fact that in both experiments dislocation-relaxation processes have been observed and reported $[3,10,11,12,13$, $14,15,16]$. Such thermally-activated relaxation processes occur as a consequence of dislocation moving in a periodic lattice potential i.e. by dislocation overcoming the Peierls potential with the help of coherent atomic thermal fluctuations $[3,11]$. In the MAE experiment the dislocation-relaxation processes may occur as the consequence of interaction between dislocations and Bloch walls [14, 17], so there is no reason to discard possibility to observe the complementarity between IF and MAE techniques in that respect too.

In $\alpha$-Fe at least three different dislocation-relaxation processes are observed in the temperature dependent IF spectra, and are denoted as $\alpha$ (around $30 \mathrm{~K}$ ), $\beta$ (around $240 \mathrm{~K}$ ), and $\gamma$ (around $330 \mathrm{~K}$ )-peaks (measured at about $1 \mathrm{~Hz}$ ) [10]. In addition, the cold-worked samples with increased carbon content exhibit the peak at about $520 \mathrm{~K}$ which occurs as a consequence of carbon-dislocation interaction e.g. SnoekKöster-relaxation. Interestingly, magnetic relaxation peaks which were associated to the thermal activation of dislocations are observed at $18 \mathrm{~K}, 430 \mathrm{~K}, 513 \mathrm{~K}$ and $625 \mathrm{~K}$ $[14,15,17,18]$. The properties of high temperature peaks strongly depend on carbon content, so they are assigned as the magnetic analogue of Snoek-Köster relaxation process. The low temperature peak $(18 \mathrm{~K})$ could be correlated to the $\alpha$-relaxation according to its temperature position, but strong doubts exist in the literature [18]. Most intriguing temperature region is around $200 \mathrm{~K}$ - $300 \mathrm{~K}$ since, due to the presence of carbon and nitrogen Snoek relaxation processes (290 K and $320 \mathrm{~K}$ measured at about $1 \mathrm{~Hz}$ [8]) it has been argued that the $\gamma$-relaxation is almost fully suppressed [19]. Still, most of the cold-worked iron alloys and steels show the existence of complex dislocationrelated relaxation processes in the temperature region around $200 \mathrm{~K}-300 \mathrm{~K}$ [20], which 
are not fully understood [21].

This work gives additional information about defect dynamics in iron-copper alloys, which can be used for better understanding of mechanical behavior of these alloys [22]. In this study we performed the MAE and IF measurements of non-deformed and coldworked low-carbon $\alpha$-Fe, and MAE measurements of thermally aged $\mathrm{Fe}-1 \% \mathrm{Cu}$ alloy focusing on the temperature region between $200 \mathrm{~K}$ and $500 \mathrm{~K}$. In both materials we observed distinct relaxation processes at about $320 \mathrm{~K}$ which occur as a consequence of the plastic deformation. The numerical analysis of its activation energy indicates that this structure can be assigned to the dislocation-relaxation process equivalent to the IF dislocation-relaxation process, with the activation energy of about 1.00 to $1.16 \mathrm{eV}$. Moreover, we analyze the behavior of the MAE relaxation processes in $\mathrm{Fe}-1 \% \mathrm{Cu}$ alloy as a function of aging times. We found that all peaks, including dislocation peak, show the same behavior as analogous processes observed by the IF technique.

\section{Experiment}

The $\alpha$-Fe alloy is fabricated by the zone refining method. The Fe- $1 \% \mathrm{Cu}$ alloy is prepared by argon-arc melting a low carbon steel in air, and adding the corresponding weight percent of pure copper. The details of the sample preparation are published elsewhere $[23,24,25]$. The chemical composition of the material used in this study is given in table 1.

Table 1. The nominal composition of investigated alloys.

\begin{tabular}{ll}
\hline Material & Nominal composition (wt. \%) \\
\hline$\alpha-\mathrm{Fe}$ & $(\sim 30-40 \mathrm{ppm} \mathrm{C})$ \\
$\mathrm{Fe}-1 \% \mathrm{Cu}$ & $1 \% \mathrm{Cu}(\sim 70-100 \mathrm{ppm} \mathrm{C})$ \\
\hline
\end{tabular}

The various stages of copper precipitation are achieved by a thermal aging process of $\mathrm{Fe}-1 \% \mathrm{Cu}$ samples, consisting of time-dependent heat treatments at $773 \mathrm{~K}\left(500{ }^{\circ} \mathrm{C}\right)$ in argon atmosphere, and subsequent fast quenching into water. The duration of heat treatments varied from $0.1 \mathrm{~h}$ to $480 \mathrm{~h}$. This aging temperature is chosen in order to achieve the peak hardening in a reasonable time $(15 \mathrm{~h})$ [26], while different aging times are chosen in order to create different hardening stages.

The MAE measurements are performed in the temperature range $200 \mathrm{~K}<T<$ $500 \mathrm{~K}$, by using an open magnetic circuit, working at $275 \mathrm{~Hz}$ and measuring the time dependence of the reciprocal value of initial susceptibility $\chi$, i.e. the initial reluctivity, $r(t, T)=\frac{1}{\chi(t, T)}[27]$. The typical sample size is $1.3 \mathrm{~mm} \times 1.3 \mathrm{~mm} \times 30 \mathrm{~mm}$. The data acquisition of the different susceptibility isotherms started at $1 \mathrm{~s}\left(t_{1}\right)$ after a well defined field metric demagnetization of the sample and ended at $t_{2} \sim 180 \mathrm{~s}$.

The IF spectra are measured in an inverted torsional pendulum, working at the frequency of about $1.8 \mathrm{~Hz}$, in a temperature range from $100 \mathrm{~K}$ to $600 \mathrm{~K}$. From the free decay signal, the resonance frequency, $\omega$, and the internal friction coefficient, $Q^{-1}$, are 


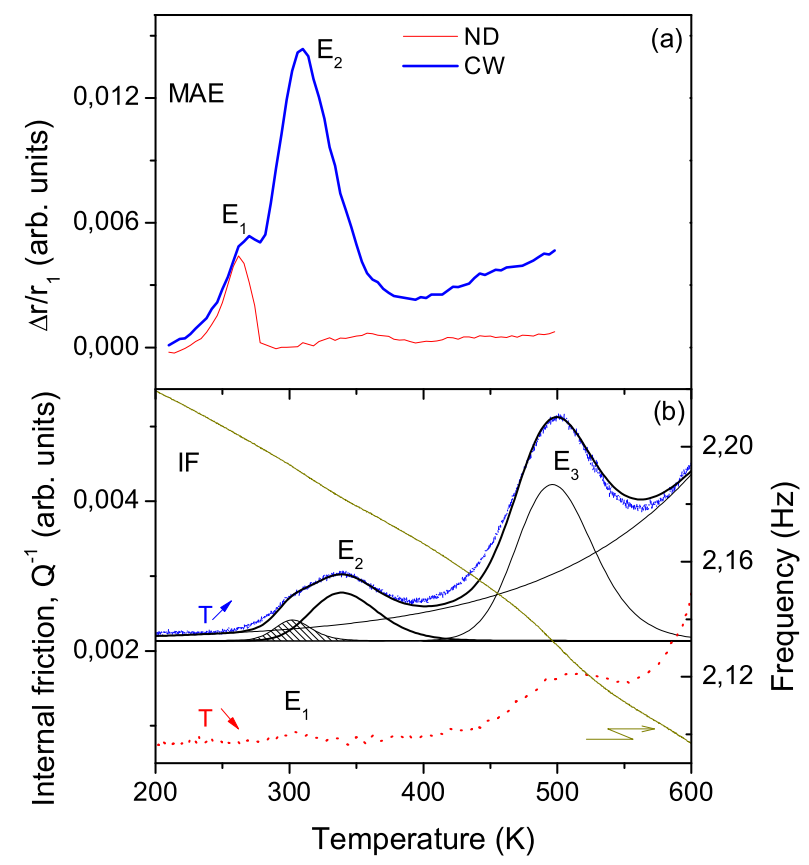

Figure 1. Magnetic after-effect (a) and internal friction (b) spectra as a function of temperature of non-deformed (ND) and cold-worked (CW), as-provided $\alpha$-Fe samples.

determined. The $Q^{-1}$ is proportional to the ratio of the energy dissipated during one cycle to the maximum elastic energy stored in the sample. The measurements have been performed at a strain amplitude of about $10^{-4}$, in a He atmosphere with a heating rate of about $1.5 \mathrm{~K} / \mathrm{min}$, and no magnetic field is applied. Since there is no change of the magnetic interaction in the materials in the temperature region considered in this work, the change of the IF background due to application of the magnetic field is a constant value and does not depend on the temperature. Because of that, the measurements with or without the magnetic field will lead to the same conclusions.

A second set of samples is, prior to the measurements, subjected to a torsional cyclic plastic deformation in a consistent way at room temperature. The degree of deformation is estimated as $\beta \mathrm{d} / \mathrm{L}$, where $\beta, \mathrm{d}$ and $\mathrm{L}$ are twisting angle, diameter and sample length, respectively.

\section{Results and discussion}

The temperature dependent MAE and IF spectra of non-deformed and cold-worked $\alpha$ Fe samples are shown in figure 1. In the case of non-deformed alloys, by increasing the temperature, the MAE spectra exhibit a peak at about $260 \mathrm{~K}$, denoted as $\mathrm{E}_{1}$. On the basis of its overall shape, the temperature position and the full width at half maximum (FWHM $\sim 30 \mathrm{~K}$ ), the peak is assigned to the Snoek-relaxation of carbon interstitials [8]. As a consequence of plastic deformation, the MAE spectra exhibit the appearance of an additional structure, denoted as $\mathrm{E}_{2}$ and centered around $320 \mathrm{~K}$, see figure 1a. The FWHM of the $\mathrm{E}_{2}$ peak is about $80 \mathrm{~K}-100 \mathrm{~K}$ which indicates that this relaxation is 


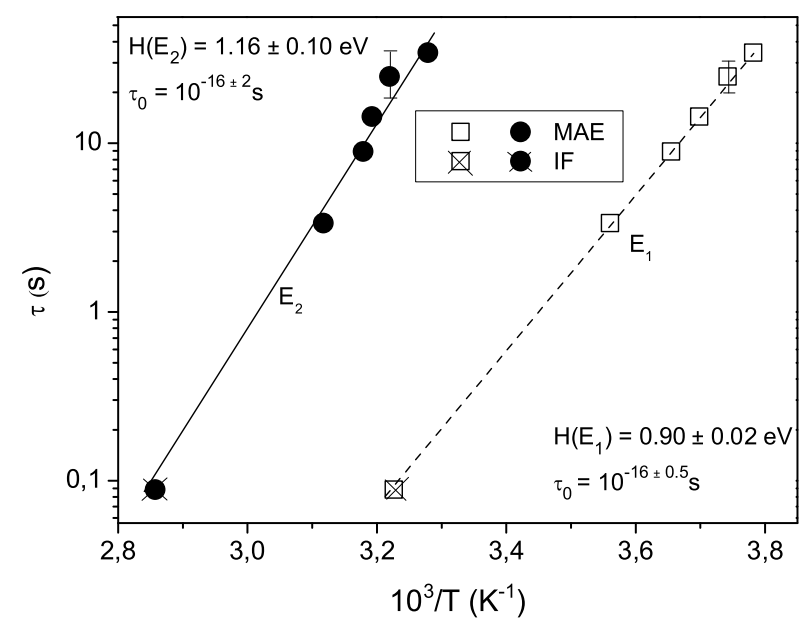

Figure 2. Arrhenius plot for both $E_{1}$ and $E_{2}$ peaks observed in the spectra of plastically deformed $\alpha$-Fe alloy. The MAE data are obtained from isochronal curves of $\mathrm{t}_{2}=8 \mathrm{~s}, 32 \mathrm{~s}, 60 \mathrm{~s}, 120 \mathrm{~s}$ and $180 \mathrm{~s}$.

governed by a distribution of relaxation times which is typical for spatially extended defects such as dislocations. The temperature dependent IF spectra of the cold-worked sample in the heating (dashed line) and cooling (dotted line) regimes are presented in figure 1b. The internal friction spectra in the cooling regime are shifted to lower values in order to improve the graph clarity. The temperature dependence of the frequency is shown only for the heating regime. The relaxation peaks in the heating regime spectrum are analyzed by a standard Debye-relaxation expression [1]:

$$
Q^{-1} \sim \Delta \frac{\omega \tau}{1+(\omega \tau)^{2}}
$$

where $\Delta$ is the relaxation strength, and $\tau$ is the relaxation time which follows an Arrhenius equation $\tau=\tau_{0} \exp \left(\frac{H}{k T}\right)$ with the activation enthalpy $\mathrm{H}$. The results of the fit, including separate contributions of each relaxation process and an exponential background, are shown by full lines. By increasing the temperature the heating-regime spectrum exhibits three peaks centered around $310 \mathrm{~K}, 320 \mathrm{~K}$, and $500 \mathrm{~K}$, which on the basis of previous investigations are recognized as the Snoek-, cold-work-dislocation (CWD) - peak, and the Snoek-Köster relaxation processes [8, 28, 29], respectively. In a cooling regime, the $\mathrm{E}_{2}$ peak is fully annealed, while the carbon related peaks, e.g. the Snoek- and Snoek-Köster peaks are still clearly visible.

The activation energies of the $\mathrm{E}_{1}$ and $\mathrm{E}_{2}$ relaxation processes observed in MAE and IF spectra are analyzed on the basis of two methods.

(a) The Arrhenius plots. The relaxation times involved in both MAE and IF measurements follow an Arrhenius equation with identical values of activation energy, $\mathrm{H}$, and pre-exponential factor, $\tau_{0}[30]$. The $\tau(\mathrm{MAE})=\left(\mathrm{t}_{2}-\mathrm{t}_{1}\right) / \ln \left(\mathrm{t}_{2} / \mathrm{t}_{1}\right)$ and $\tau(\mathrm{IF})=$ $(2 \pi \omega)^{-1}$, where $t_{1}$ and $t_{2}$ are the two measuring time points characterizing two isochronal MAE curves. In figure 2, $\tau$ is plotted as a function of $10^{-3} / \mathrm{T}$ for the corresponding peaks in several isochronal MAE curves as well as for the IF peaks. In such plots the 


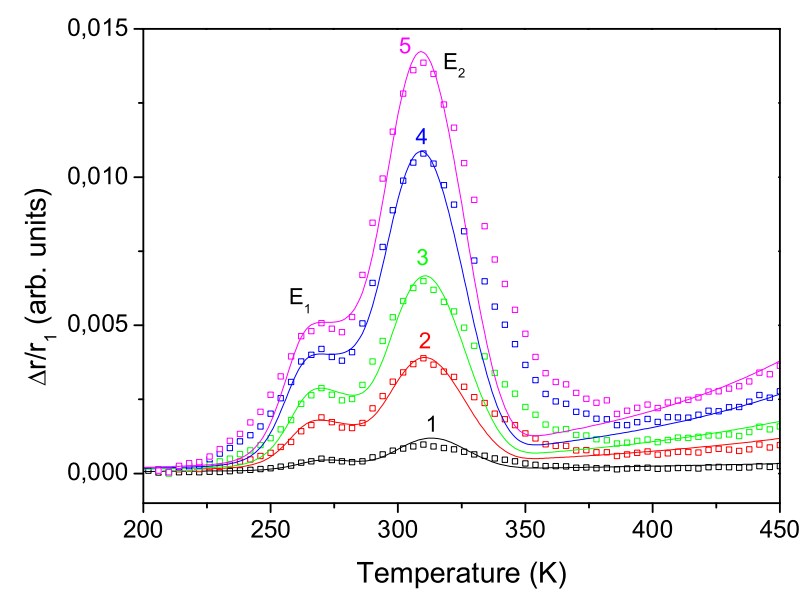

Figure 3. Isochronal magnetic relaxation spectra fitted by numerical technique. $t_{1}$ $=1 \mathrm{~s}, \mathrm{t}_{2}=8 \mathrm{~s}(1), 32 \mathrm{~s}(2), 60 \mathrm{~s}(3), 120 \mathrm{~s}(4), 180 \mathrm{~s}(5)$. Symbols correspond to measured points and lines to their numerical approximations.

straight lines connecting the MAE and IF results are expected if the results belong to the same relaxation process [30]. Indeed, this is confirmed for both $\mathrm{E}_{1}$ and $\mathrm{E}_{2}$ relaxation peaks, see figure 2 . The estimated parameters of the $\mathrm{E}_{1}$ and $\mathrm{E}_{2}$ relaxation processes are collected in table 2 .

(b) Numerical technique. Figure 3 shows isochronal relaxation curves, i.e. the temperature dependent relative change of the reluctivity, $\mathrm{r}$ :

$$
\frac{\Delta r}{r_{1}}=\frac{\Delta r\left(t_{1}, t_{2}, T\right)}{r\left(t_{1}, T\right)}=\frac{r\left(t_{2}, T\right)-r\left(t_{1}, T\right)}{r\left(t_{1}, T\right)} .
$$

$t_{1}=1 \mathrm{~s}$, and the curves are shown for various $t_{2}$ in the range from $8 \mathrm{~s}$ to $180 \mathrm{~s}$. The calculated curves (full lines) are approximated by the sum of separate contributions including two relaxation processes and an exponential background. The numerical fit of two relaxation processes is performed on the basis of the point defect model [31]:

$$
\Delta r\left(t_{1}, t_{2}, T\right)=A(T)\left\{\left[E_{i}\left(-t_{1} / \tau_{1}\right)-E_{i}\left(-t_{2} / \tau_{1}\right)\right]-\left[E_{i}\left(-t_{1} / \tau_{2}\right)-E_{i}\left(-t_{2} / \tau_{2}\right)\right]\right\} .
$$

The $\mathrm{A}(\mathrm{t})$ and $\mathrm{E}_{i}\left(-\mathrm{t}_{i} / \tau_{k}\right)$ represent the temperature-dependent relaxation amplitude, and exponential integral with the measuring times $t_{1}$ and $t_{2}$, respectively. $\tau_{1}$ and $\tau_{2}$ are the relaxation times as obtained from the Arrhenius equation for the minimum $\left(\tau_{1}=\tau_{0}\right.$ $\left.\exp \left(\frac{H_{1}}{k T}\right)\right)$ and maximum $\left(\tau_{2}=\tau_{0} \exp \left(\frac{H_{2}}{k T}\right)\right)$ energy across the range $\Delta \mathrm{H}$ (i.e. $\mathrm{H}_{1}=\mathrm{H}$ $\Delta \mathrm{H} / 2 ; \mathrm{H}_{2}=\mathrm{H}+\Delta \mathrm{H} / 2$ ). In other words, $\tau_{1}$ and $\tau_{2}$ are the lower and upper bounds of relaxation times at temperature $\mathrm{T}$. For each relaxation peak several isochronal curves are simultaneously fitted until the best agreement between measured and calculated spectra are obtained. This allows the estimation of the relaxation processes parameters $\mathrm{H}, \Delta \mathrm{H}$ and $\tau_{0}$ which are collected in table 2 .

Both methods for both relaxation processes give very similar results. In the case of the Snoek-peak, our results agree well with the literature [9]. For the $\mathrm{E}_{2}$ peak, it is found that the activation energy is very close to the value of the $\gamma$-peak observed in the IF spectra $(1.06 \mathrm{eV})[11]$. Besides, the FWHM of the $\mathrm{E}_{2}$ peak $(\Delta \mathrm{H}=0.15 \mathrm{eV})$ which 
Table 2. Summary of results obtained from analyses of magnetic relaxation processes due to different techniques.

\begin{tabular}{|c|cc|ccc|}
\hline & \multicolumn{2}{|c|}{ Arrhenius } & \multicolumn{3}{c|}{ Numerical } \\
\cline { 2 - 6 } & $\mathrm{H}(\mathrm{eV})$ & $\tau_{0}(\mathrm{~s})$ & $\mathrm{H}$ & $\Delta \mathrm{H}(\mathrm{eV})$ & $\tau_{0}(\mathrm{~s})$ \\
\hline $\mathrm{E}_{1}$ & $0.90 \pm 0.04$ & $10^{-16 \pm 0.5}$ & $0.86 \pm 0.04$ & 0.04 & $10^{-16 \pm 0.5}$ \\
$\mathrm{E}_{2}$ & $1.16 \pm 0.1$ & $10^{-16 \pm 2}$ & $1.00 \pm 0.02$ & 0.15 & $10^{-16 \pm 2}$ \\
\hline
\end{tabular}

is proportional to the distribution of relaxation times, is also in good agreement with IF data. Because of that, we assign the $\mathrm{E}_{2}$ peak to dislocation-relaxation process. The agreement between measured and calculated spectra is found to be not so good for the tails of relaxation distribution function. This is the consequence of non-adequacy of the model, which is strictly specking valid only for the point defect relaxations[18]. However, this disagreement do not endanger the determination of the activation energy. Due to non-adequacy of the model, one can be concerned about the precise determination of FWHM only, but this result also indicates that the relaxation process can not be associated to the point defect relaxations.

Further, we analyze the MAE spectra of thermally aged $\mathrm{Fe}-1 \% \mathrm{Cu}$ alloys. The temperature dependent non-deformed and cold-worked MAE spectra of Fe-1\%Cu alloy thermally aged at $773 \mathrm{~K}$ for $20 \mathrm{~h}$ are shown in figure 4 . In cold-worked samples, the peak at about $320 \mathrm{~K}$ is observed in addition to the Snoek-peak. This peak clearly appears as the consequence of plastic deformation, with the intensity which increases by increasing the degree of plastic deformation, see figure 4. Moreover, the peak position at about $320 \mathrm{~K}$ corresponds well to the $\mathrm{E}_{2}$ peak position observed in $\alpha$-Fe.

Figures 5 and 6 show the temperature dependent MAE spectra of non-deformed and cold-worked thermally aged Fe-1\%Cu samples, respectively. The intensity of Snoek peak of the non-deformed samples, denoted as $\mathrm{E}_{1}{ }^{N D}$, decreases by increasing the aging time, until about $180 \mathrm{~h}$ where it diminishes. For the sample aged for $0.1 \mathrm{~h}$, the carbon Snoekpeak is found to be about 2.5 times more intense in comparison with the Snoek-peak in $\alpha$-Fe alloy, see figure 1 . This observation nicely correlates with reported carbon contents in these alloys, see table 1 . The temperature position of the peaks maximum as well as the FWHM do not change as a function of aging time. In the spectra of cold-worked samples the Snoek-peak and cold-work-dislocation peak are marked as $\mathrm{E}_{1}{ }^{C W}$ and $\mathrm{E}_{2}$, respectively. The spectra are clearly more complex in comparison with non-deformed samples because of the partial overlap of the peaks.

The main change of the MAE spectra, caused by different thermal aging times, is observed in the behavior of peak intensities. The analysis of the peak intensities is performed by fitting the spectra with Gaussian peak shapes, since it produces a much better fit in comparison with the point defect model, see (3). The integrated intensities of the $E_{1}$ peak, observed in the MAE spectra of both non-deformed (ND) and coldworked $(\mathrm{CW})$ samples, as well as the intensities of the $\mathrm{E}_{2}$ peak are presented in figures $7 \mathrm{a}, \mathrm{b}$ as a function of the aging time. Their behavior is compared with results from 


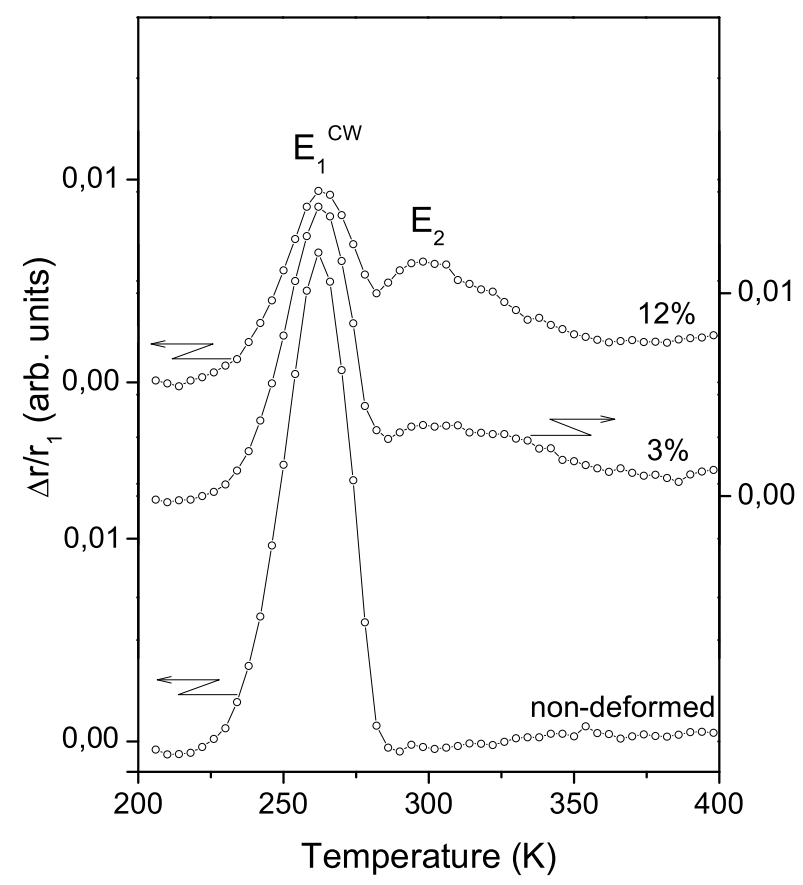

Figure 4. Magnetic after-effect spectra as a function of temperature of thermally aged for $20 \mathrm{~h}, \mathrm{Fe}-1 \% \mathrm{Cu}$ samples, with different degree of plastic deformation. The degrees of plastic deformations are mentioned in the figures. The circles are the experimental data and full lines are results of the fit.

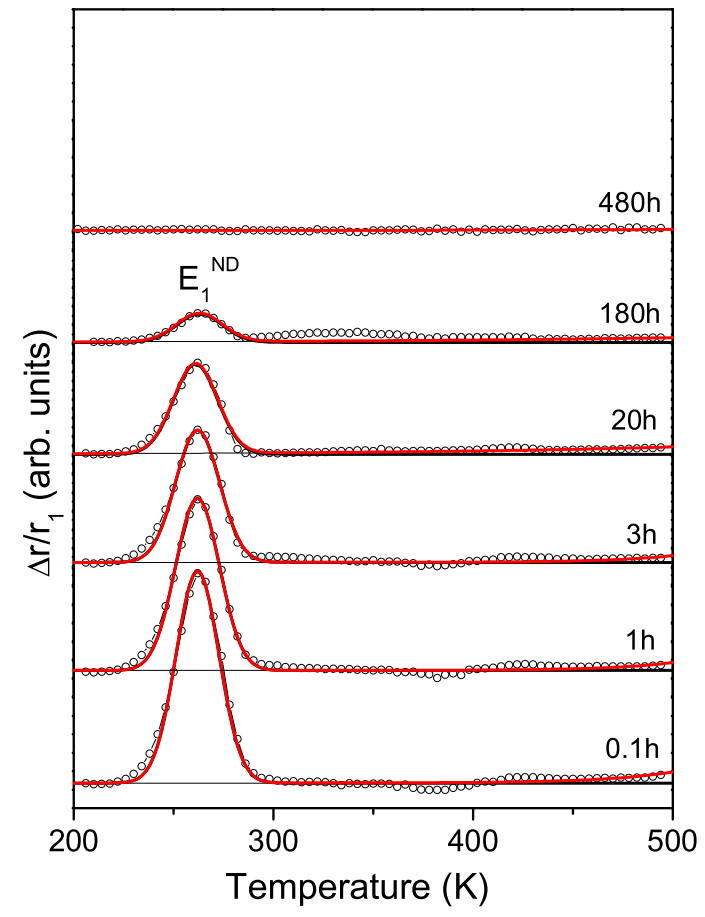

Figure 5. Magnetic after-effect spectra as a function of temperature of non-deformed (ND), thermally aged $\mathrm{Fe}-1 \% \mathrm{Cu}$ samples. The circles are the experimental data and full lines are results of the fit. Aging times are mentioned in the figure. 


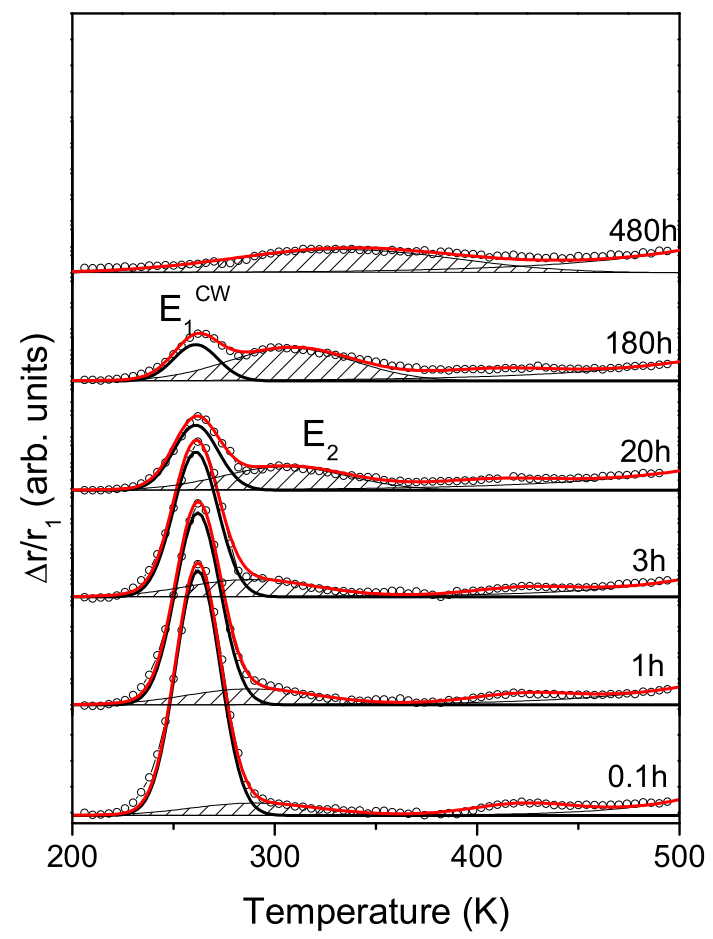

Figure 6. Magnetic after-effect spectra as a function of temperature of cold-worked $(\mathrm{CW})$, thermally aged $\mathrm{Fe}-1 \% \mathrm{Cu}$ samples. The circles are the experimental data and full lines are results of the fit. Aging times are mentioned in the figure.

already measured IF spectra [32] here reproduced at figures $7 \mathrm{c}, \mathrm{d}$.

As already discussed in our previous work [32], the intensity decrease of the Snoek peak $\left(\mathrm{E}_{1}{ }^{N D}\right)$ in non-deformed samples indicates a strong influence of the copper precipitates to the carbon kinetics, see figure 7a. Indeed, the process of carbon redistribution is most probably a result of the lattice strain field, created by the growth of copper precipitates. This could cause an enhanced carbon migration in the lattice, leading to carbon segregation at the precipitate interfaces or at the grain boundaries. This effect is also confirmed in the cold-worked samples, on the basis of the $\mathrm{E}_{1}^{C W}$ peak intensity behavior. The only difference is that the intensity values of the $\mathrm{E}_{1}^{C W}$ peak are situated below the $\mathrm{E}_{1}{ }^{N D}$ peak intensities, due to a partial segregation of carbon atoms to dislocations during plastic deformation. The MAE and IF peak intensity behaviours disagree with each other at very short aging times (up to $1 \mathrm{~h}$ ), see figure $7 \mathrm{c}$. This is an early and intense precipitation regime which could cause large variation of the Snoek-peak intensities (large error-bars).

The $\mathrm{E}_{2}$ peak, in both cases, exhibits a gradual increase reaching a local maximum at about $15 \mathrm{~h}$, and the second increase at high aging times, see figures $7 \mathrm{~b}$, d. The intensity increase up to $15 \mathrm{~h}$ is a consequence of dislocation-precipitate interaction and can be correlated to the peak hardening [32]. Namely, the growth of copper precipitates at early precipitation stages obstructs the dislocation motion, and increases the dislocation density in the material, which is manifested as the $\mathrm{E}_{2}$ peak intensity increase. Second $\mathrm{E}_{2}$ 


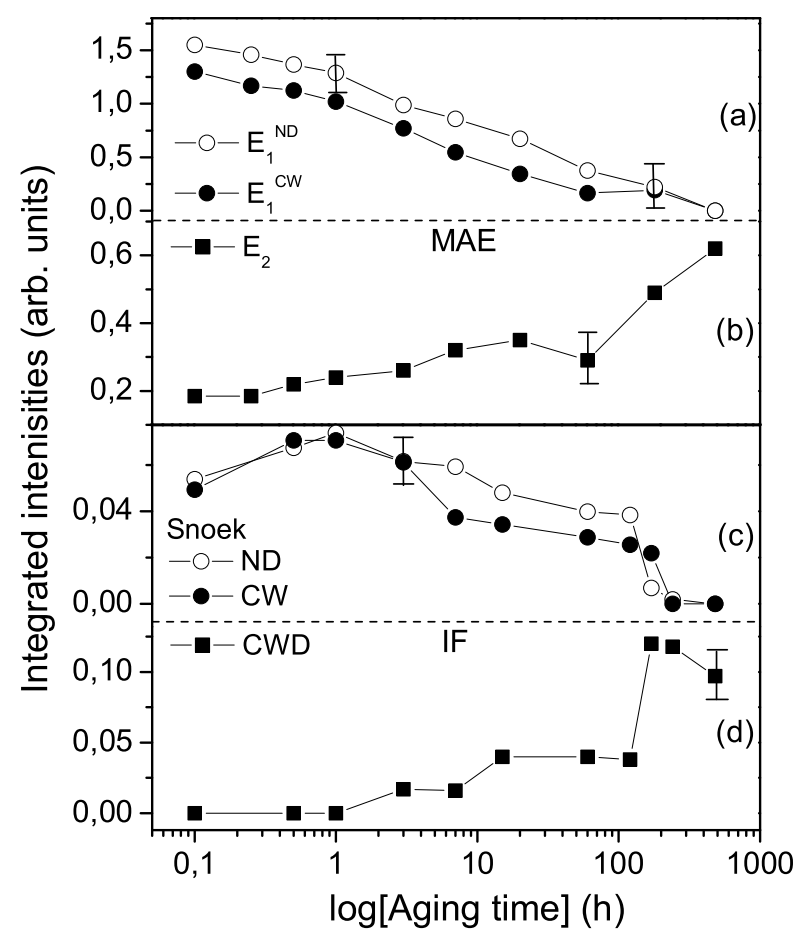

Figure 7. The integrated intensities as a function of the aging time of the $\mathrm{E}_{1}$ and $\mathrm{E}_{2}$-peaks obtained by MAE (a and b) measurements, respectively. The integrated intensities as a function of the aging time of the Snoek $\left(\mathrm{E}_{1}\right)$ - and cold-work-dislocation $\left(\mathrm{CWD}-\mathrm{E}_{2}\right.$ )-peaks obtained by IF (c and d) measurements, respectively. Non-deformed - ND and cold-worked - CW samples.

intensity increase, observed after $180 \mathrm{~h}$, is a consequence of carbon redistribution. Due to carbon removal from the lattice the $\mathrm{E}_{2}$ dislocation-relaxation peak gains intensity at the expense of Snoek-Köster relaxation peak (not observed in MAE, but clearly observed in the IF experiment [32]).

Finally, the most important observation is the existence of the similarities between intensity behavior of MAE and IF cold-worked relaxation-peaks. This indicates that the same features are observed in both MAE and IF spectra. This concerns both Snoek and cold-worked peaks. This fact provides an additional proof of MAE-IF complementarity already observed in $\alpha$-Fe concerning dislocation-related relaxation process.

\section{Conclusion}

Magnetic after-effect measurements were performed in order to study dislocation dynamics and dislocation related relaxation processes in Fe-based alloys. By analyzing the temperature-dependent isochronal relaxation spectra of non-deformed and coldworked $\alpha$-Fe and thermally aged $\mathrm{Fe}-1 \% \mathrm{Cu}$, we observed the structure at about 320 $\mathrm{K}$ which uniquely occurs as a consequence of plastic deformation and can be clearly distinguished from the relaxation of carbon interstitials at about $260 \mathrm{~K}$. This peak is, on the basis of relaxation-process parameters such as the activation energy, half-width 
and intensity assigned to the dislocation relaxation process.

\section{Acknowledgement}

This research is carried out in the frame of FWO project No: G.0127.08.

\section{References}

[1] De Batist R 1972 Internal Friction of Structural Defects in Crystalline Solids (North Holland American Elsevier, Amsterdam - London - New York) p 85

[2] Nowick A S and Berry B S, Anelastic relaxation in Crystalline Solids (Academic New York, 1972).

[3] Bordoni P G 1949 Ric. Sci. 19851

[4] Blythe H J, Lopez-Cabido J I and Castro J 1997 J. Phys. D: Appl. Phys. 301468

[5] Walz F, Brabers V A M and Kronmüller H J. Phys: Cond. Matter. 22046007

[6] Walz F and Blythe H J 1984 Appl. Phys. A 3457

[7] Hofmann A, Schüle P, Moser N, Kronmüller H, Jäger H and Dworschak F 1988 Physica C 153 341

[8] Snoek J L 1941 Physica 8711

[9] Walz F, Weller M and Hircher M 1996 Phys. Status Solidi A 154765

[10] Fantozzi G, Esnouf C, Benoit W and Ritchie I G 1982 Progr. Mater. Sci. 27311

[11] Mizubayashi H, Kronmüller H and Seeger A 1985 J. Phys. Colloq. 10309

[12] Weller M 1983 J. Physique 44 C-9

[13] Ritchie I G, Dufresne J and Moser P 1980 Phys. Stat. Sol. A 61591

[14] Kuke A, Kronmüller H and Schultz H 1969 Phys. Stat. Sol. 36 K161

[15] Kronmüller H, Steeb H and König N 1976 Il Nuovo Cim. 33 B 205

[16] Blythe H J and Walz F 1985 Phys. Stat. Sol. A 89213

[17] Blythe H J and Kronmüller H 1971 Phys. Stat. Sol. A 5191

[18] Walz F, Blythe H J and Kronmüller H 1980 Phys. Stat. Sol. A 61607

[19] Benoit W 2001 Mechan. Spectrosc. $Q^{-1}$ 363-3 158

[20] Konstantinović M J 2008 Phys. Rev. B 78052104

[21] Magalas L B, Moser P and Ritchie I G 1983 J. Phys. 44 C9-645

[22] Vandenbossche L, Konstantinovic M, Almazouzi A and Dupr L 2007 J. Physics D: Appl. Phys. 404114

[23] Verheyen K, Jardin M and Almazouzi A 2006 J. Nucl. Mater. 351209

[24] Konstantinović M J, Almazouzi A, Scibetta M and van Walle E 2007 J. Nucl. Mater. 362283

[25] Lambrecht M $2009 \mathrm{PhD}$ Thesis (Ghent University) p 63

[26] Kamada Y, Nishino Y, Hosoi S, Tamaoka S, Ide N, Kikuchi H and Kobayashi S 2009 Mat. Scien. Engin. A 521-22 209

[27] Minov B, Vandenbossche L, Konstantinović M J and Dupré L 2010 IEEE Trans. Magn. 46521

[28] Van Ouytsel K, De Batist R and Schaller R 2003 J. Press. Vess. Pip. 80275

[29] Köster W, Bangert L and Hahn R 1954 Arch Eisenhüttenw 25569

[30] Diehl J, Mensch W and Weller M 1977 Phys. Status Solidi A 43 K179

[31] Walz F and Kronmüller H 1994 Phys. Stat. Sol. B 181485

[32] Minov B, Dupré L and Konstantinović M J 2010 (Preprint/arXiv:1008.5262) 